\title{
Gradual weaning does not improve performance for calves with low starter intake at the beginning of the weaning process
}

\author{
C. M. M. Bittar, ${ }^{*}$ M. P. Gallo, J. T. Silva, M. R. de Paula, M. Poczynek, and G. B. Mourão \\ Department of Animal Science, University of Sao Paulo, Piracicaba, SP 13418900 Brazil
}

\begin{abstract}
The weaning process may cause intense stress for dairy calves, even when low volumes of liquid diet are fed. Management tools that increase the intake of solid feeds, such as gradual weaning, can provide better physiological and metabolic conditions through better ruminal development, leading to better adaptation to ruminant metabolism and aiding in stress mitigation. The objective of this study was to evaluate the effects of 2 weaning protocols and 2 levels of concentrate intake on the performance and physiological and behavioral variables related to stress in dairy calves. Thirty-six newborn male Holstein calves were used in a randomized block design with a $2 \times 2$ factorial arrangement: 2 weaning strategies, abrupt or gradual, and 2 levels of concentrate intake at $5 \mathrm{wk}$ of age, high $(>350 \mathrm{~g} / \mathrm{d})$ or low $(\leq 350 \mathrm{~g} / \mathrm{d})$. Calves were equally managed until they were 5 wk of age and then grouped according to concentrate intake. Statistical analyzes were performed using the MIXED procedure of SAS software (SAS Institute Inc., Cary, NC), and no significant interaction was observed between studied factors (weaning method and starter intake level); therefore, we considered each factor separately and their interactions with age. The highest dry matter intake and concentration of $\beta$-hydroxybutyrate were recorded for animals with a high level of starter intake independent of the weaning method. Structural growth (cm/wk) and average daily gain were superior for calves with high starter intake, but weaning method had no effect. The gradual weaning protocol increased the time eating starter, regardless of the level of concentrate intake. Even animals with low concentrate intake that were weaned abruptly showed levels of cortisol and acid-soluble glycoprotein within normal physiological levels. Apparently, other factors besides the milk supply affect the starter intake level of calves in a conventional feeding program. The
\end{abstract}

Received September 19, 2019.

Accepted January 9, 2020.

*Corresponding author: carlabittar@usp.br adoption of gradual weaning is not effective in improving performance when a calf has low intake $3 \mathrm{wk}$ before weaning is complete, but it reduced vocalization on $\mathrm{d}$ 2 postweaning.

Key words: animal behavior, calf performance, ruminal development, vocalization

\section{INTRODUCTION}

Feed management of dairy calves has a marked influence on the transition from a preruminant to a functional ruminant condition, mainly through the early supply of starter concentrate. Although several studies have shown the importance of feeding higher volumes of liquid diet, producers in many countries are still feeding only 4 to $5 \mathrm{~L} / \mathrm{d}$ of milk to dairy calves (Vasseur et al., 2010; USDA-APHIS, 2014; Santos and Bittar, 2015). The main reasons cited for this feeding management are lower costs and easy weaning because of the increased starter intake (Santos and Bittar, 2015).

The starter concentrate intake during preweaning is inversely correlated with the milk volume ingested by the animal (Gelsinger et al., 2016). However, other factors may affect starter intake, such as the incidence of diseases (Wenge et al., 2014) and vigor and vitality early in life (Neave et al., 2018). In their summary of several studies, Hill et al. (2013) listed important factors that may affect solid feed intake, such as solid feed particle size, feeding hay, liquid diet feeding volume, and gradual weaning. In addition, several studies reported a very high coefficient of variation or standard error of mean preweaning solid feed intake (Kertz et al., 1979), suggesting that the regulation of solid feed intake is multifactorial.

The initial recommendation for starter feed intake for adequate weaning of Holstein calves was approximately 700 to $800 \mathrm{~g} / \mathrm{d}$ for 3 consecutive days (Quigley, 1996). However, because birth weight varies within breeds, Greenwood et al. (1997) suggested that adequate intake should be at least $1.5 \%$ of an animal's birth weight. More recently, Stamey et al. (2012) suggested that calves should be eating $1.0 \mathrm{~kg} / \mathrm{d}$ for adequate weaning. All these recommendations represent an attempt 
to understand the minimum intake to ensure rumen development for adequate weaning.

Calves that have low concentrate intake experience increased stress at weaning, which results in increased susceptibility to disease and weight loss postweaning (Miller-Cushon and DeVries 2015). The stress at weaning can be evaluated by behavioral changes, such as frequency of vocalization and motor activity (Veissier et al., 2013), as well as by blood variables, such as cortisol and acute phase proteins (Lomborg et al., 2008). Some studies have shown that when starter intake is adequate, performance between abruptly and gradually weaned animals has no major differences (Roth et al., 2009; Bach et al., 2010). However, gradual weaning may help stimulate concentrate intake before weaning, improving subsequent performance for calves receiving high volumes of liquid diet (Steele et al., 2017; Klopp et al., 2019).

Sweeney et al. (2010) have shown that gradual weaning is more effective in increasing calf starter intake relative to abrupt weaning. However, the increase in starter concentrate intake was not enough to compensate for the decreased milk intake, resulting in lower energy intake. In this case, when gradual weaning starts at an early age, calves will have lower ADG and increased stress. When weaning starts later, the transition is smooth and calves will cope with decreased milk intake by increasing their starter intake without experiencing a significant decrease in energy intake. On the other hand, calves that are abruptly weaned may have higher ADG during the milk-feeding period, but performance will be decreased afterward. The success of gradual weaning appears to be correlated with the calf starter intake at the beginning of the process (Sweeney et al., 2010).

The gradual weaning method has been studied more frequently with calves receiving higher volumes of milk. When done properly, the method has been associated with interesting results, particularly regarding starter intake and timing of liquid diet reduction (Eckert et al., 2015; Klopp et al., 2019). The literature also shows that gradual weaning may result in low energy intake for calves fed high volumes of liquid diet (Sweeney et al., 2010; Steele et al., 2017). For calves fed approximately $4 \mathrm{~L} / \mathrm{d}$, gradual weaning may be even more complicated if they have low starter intake, because this feeding volume is not correlated with decreased solid feed intake. Thus, we hypothesized that gradual weaning will not attenuate stress or improve performance for calves fed $4 \mathrm{~L} / \mathrm{d}$ of milk replacer $(500 \mathrm{~g} / \mathrm{d})$ that have low starter intake $(\leq 350 \mathrm{~g} / \mathrm{d})$. The objective of the present study was to evaluate the effects of 2 starter intake levels and 2 weaning strategies on performance, behavior, metabolism, and stress indicators.

\section{MATERIALS AND METHODS}

The Animal Research Ethics Committee of the Luiz de Queiroz College of Agriculture/University of São Paulo approved all procedures involving animals in this study.

\section{Animals, Experimental Design, and Treatments}

Thirty-six male Holstein newborn calves (means \pm $\mathrm{SD} ; \mathrm{BW}=35.5 \pm 4 \mathrm{~kg}$ ) were separated from their dams at birth, weighed, and housed in individual hutches. Calves received $2 \mathrm{~L}$ of high-quality colostrum $(>22 \%$ Brix determined using an optic handheld refractometer; ITREF 200, Instrutemp, São Paulo, SP, Brazil) shortly after birth and every $12 \mathrm{~h}$ during the first 2 $\mathrm{d}$ of life. Calves had access to water and the starter concentrate (Rumina 18CP, Guabi Animal Nutrition, Anápolis, Brazil; 21.6\% CP, 28\% NDF, $3.168 \mathrm{Mcal} /$ $\mathrm{kg}$, DM basis) and were open bucket fed $4 \mathrm{~L} / \mathrm{d}$ of milk replacer (Sprayfo Violeta, 22 CP: 16 ether extract, 2.29 Mcal $/ \mathrm{kg}$, DM basis, diluted for $125 \mathrm{~g} / \mathrm{kg}$ of solids; Sloten do Brasil Ltda., Santa Bárbara d'Oeste, Brazil), divided into 2 meals (0700 and $1700 \mathrm{~h}$ ).

The experimental design was a randomized block design, using sex, birth weight, and birth date as a blocking factor, in a $2 \times 2$ factorial arrangement ( 2 starter concentrate levels and 2 weaning strategies). Experimental treatments were 2 weaning strategies (abrupt or gradual) applied in 2 groups of high and low starter intake at $35 \mathrm{~d}$ of age. Thus, all animals were handled in the same way until $35 \mathrm{~d}$ of age, when they were allocated according to starter intake (high intake, $>350$ $\mathrm{g} / \mathrm{d}$; low intake, $\leq 350 \mathrm{~g} / \mathrm{d}$ ) and one of the proposed treatments: (a) abrupt weaning, low intake; (b) abrupt weaning, high intake; (c) gradual weaning, low intake; and (d) gradual weaning, high intake. All animals were weaned according to age at 8 wk of life. Abruptly weaned calves received their last milk replacer meal at the afternoon feeding on d 56 of age. Gradual weaning was performed by decreasing the milk replacer supply as follows: reduction of $1 \mathrm{~L} / \mathrm{d}$ at $42 \mathrm{~d}$ of age, feeding 1.5 $\mathrm{L}$ each meal; reduction of $1 \mathrm{~L} / \mathrm{d}$ at $49 \mathrm{~d}$ of age, feeding 1 $\mathrm{L}$ each meal; and reduction of $1 \mathrm{~L} / \mathrm{d} 2 \mathrm{~d}$ before completing $56 \mathrm{~d}$ of age, feeding $0.5 \mathrm{~L}$ each meal, with the last meal at $56 \mathrm{~d}$ of age (Figure 1). After weaning, calves remained at the individual hutches, received coast-cross hay $(6.8 \% \mathrm{CP}, 77.6 \% \mathrm{NDF}, 2.288 \mathrm{Mcal} / \mathrm{kg})$ ad libitum and were monitored until the $70 \mathrm{~d}$ of age.

\section{Measurements, Sampling, and Analyses}

Feed intake was recorded daily by weighing the feed offered and orts. Energy intake was calculated consider- 


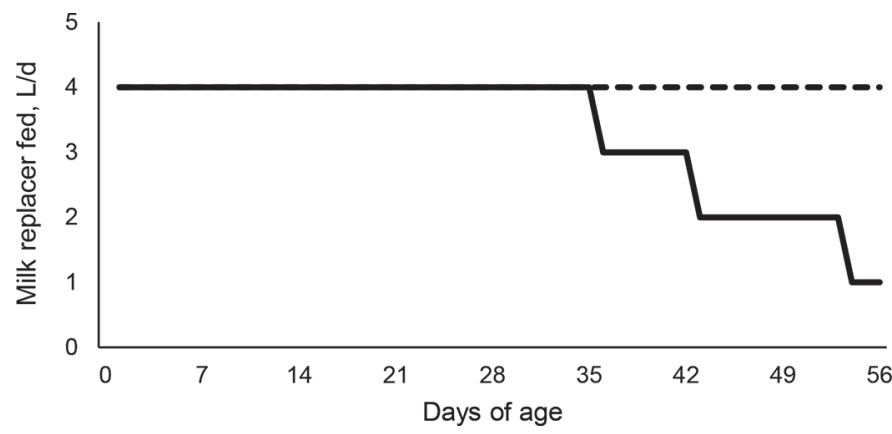

Figure 1. Liquid diet feeding program according to weaning method, abrupt (dashed line) or gradual (solid line), for a complete weaning at $56 \mathrm{~d}$.

ing crude energy content of feed (milk replacer, starter concentrate, and coast-cross hay) and daily feed intake. The calves were weighed weekly in a mechanical scale (ICS-300, Coimma Ltda., Dracena, SP, Brazil) for ADG calculation and measurements of withers height, heart girth, and hip width were taken. The fecal score was evaluated daily according to Larson et al. (1977).

Starting at the second week of age, blood samples were collected weekly by venipuncture of the jugular vein into a vacuum tube containing sodium fluoride as the antiglycolytic and potassium EDTA as the anticoagulant (Vacuette do Brazil, Campinas, SP, Brazil) for plasma or clot activator and gel (Vacuette do Brazil) for serum collection. Sampling was always performed $2 \mathrm{~h}$ after morning feeding, and the samples were immediately placed on ice. Tubes were centrifuged at $2,000 \times g$ for 15 min at $4^{\circ} \mathrm{C}$ to separate the serum or plasma, which was then stored at $-10^{\circ} \mathrm{C}$ for subsequent analysis. The metabolic indicators (glucose, total serum protein, BHB) were determined using and automated biochemistry analyzer (model SBA-200, CELM, Barueri, SP, Brazil). Commercial kits from Labtest Diagnostica SA (Lagoa Santa, MG, Brazil) were used for determination of plasma glucose (cat. no. 133-1) and total serum protein (cat. no. 99). Determination of BHB levels was carried using the RANBUT enzyme kit (RB1007; Randox Laboratories, Life Sciences Ltd., Crumlin, UK). Also, on d $-14,-7,0,1,2,3,4$, and 7 relative to weaning, blood samples were taken $30 \mathrm{~min}$ after the morning milk supply for the determination of cortisol by RIA (Assay Designs, Ann Arbor, MI); acidsoluble glycoproteins according to 2-step methods proposed by Nakajima et al. (1982) and Bradford (1976); and glucose and BHB concentrations.

\section{Behavior Evaluation}

All calves were monitored for $15 \mathrm{~h}$ by direct observation every $5 \mathrm{~min}$ as suggested by Miller-Cushon and
DeVries (2011). Observation started at $0500 \mathrm{~h}$ and ended at $2000 \mathrm{~h}$ on $\mathrm{d}-14,-7,-2,0,2$, and 7 relative to weaning, for a total observation time of $90 \mathrm{~h}$ per animal. Observations were recorded for standing or lying down, head position (up or down), feeding behaviors (eating starter feed, forage, drinking milk or water, ruminating), nonnutritive oral behaviors, and vocalization. The observers were trained before the trial to identify behaviors.

\section{Statistical Analysis}

Statistical analyzes were performed using the MIXED procedure of SAS software (2002; SAS Institute Inc., Cary, NC). All data were tested for normal distribution by the Shapiro-Wilk test, and homogeneity of the variances was assessed using the Levene test.

For the variables analyzed as repeated measures over time (weeks of age and days related to weaning), the following statistical model was used:

$$
\begin{aligned}
\mathrm{Y}_{\mathrm{ijkl}}= & \mu+\mathrm{D}_{\mathrm{i}}+\mathrm{C}_{\mathrm{j}}+\mathrm{DC}_{\mathrm{ij}}+\mathrm{b}_{\mathrm{k}}+\mathrm{w}_{\mathrm{ijk}}+\mathrm{S}_{\mathrm{l}} \\
& +\mathrm{SD}_{\mathrm{il}}+\mathrm{SC}_{\mathrm{jl}}+\mathrm{SDC}_{\mathrm{ijl}}+\mathrm{E}_{\mathrm{ijk}},
\end{aligned}
$$

where $\mu=$ general average; $D_{i}=$ fixed effect of the weaning method; $C_{j}=$ fixed starter intake level effect (high or low); $\mathrm{DC}_{\mathrm{ij}}=$ fixed effect of the interaction weaning method and starter intake level; $b_{k}=$ random block effect; $\mathrm{w}_{\mathrm{ijk}}=$ residual error $\mathrm{A} ; \mathrm{S}_{1}=$ fixed age effect; $\mathrm{SD}_{\mathrm{il}}=$ fixed effect of age interaction and weaning method; $\mathrm{SC}_{\mathrm{jl}}=$ fixed effect of the interaction of age and starter intake level; $\mathrm{SDC}_{\mathrm{ij} l}=$ effect of age interaction, weaning method, and starter intake level; and $\mathrm{E}_{\mathrm{ijkl}}=$ error residual B. The covariance matrices were tested and defined according to the lowest value obtained for Akaike's information criterion corrected. For the results interpretation and discussion, a significant effect was determined by $P \leq 0.05$, whereas $0.05<P<0.10$ was considered a tendency. For all response variables, the means were obtained through the LSMEANS command.

\section{RESULTS}

No significant interaction $(P>0.10)$ was found between the studied factors (weaning method and starter intake level), so results and discussion are presented considering each factor separately and their interactions with age.

\section{Intake and Growth Performance}

Calves weaned gradually had lower milk replacer intake $(P<0.001)$. Starter intake did not differ $(P>$ 
0.05 ) between abrupt or gradual weaning methods (Table 1). In addition, calves that had the highest starter intake at $35 \mathrm{~d}$ of age maintained the difference even after weaning $(P<0.001$; Table 1$)$. Total energy intake was higher for calves with higher starter intake. An interaction occurred between the weaning methods and the age of the animals $(P<0.001)$, and the gradually weaned calves ingested less energy in the 2 wk before weaning (Figure 2). Although the weaning method did not affect $\mathrm{ADG}$ or $\mathrm{BW}(P=0.882$ and $P=0.094$, respectively; Table 1), these variables had significant differences as a function of starter intake levels $(P<$ 0.001 and $P<0.001$; Table 1). Higher starter intake at $35 \mathrm{~d}$ of age resulted in higher ADG overall and at $70 \mathrm{~d}$ of age. Overall structural growth was superior for calves with high starter intake $(P<0.005)$. However, weaning method had no effect on structural growth when analyzed as centimeters of gain per week.

\section{Blood Metabolites}

Calves with high starter intake levels had higher glucose levels at weaning $(P<0.002$; Table 2$)$. Both the intake level and the weaning method significantly affected the BHB plasma concentrations at weaning. Thus, gradually weaned calves and calves with high starter intake levels had the highest BHB levels $(P=$ 0.03 and $P<0.001$, respectively, Table 2 ). The other metabolites were not affected by the studied factors (Table 2).

\section{Calf Behavior}

Starter intake level did not change the amount of time spent eating starter or hay during the evaluated days $(P=0.301$ and $P=0.226$, respectively; Table 3$)$.

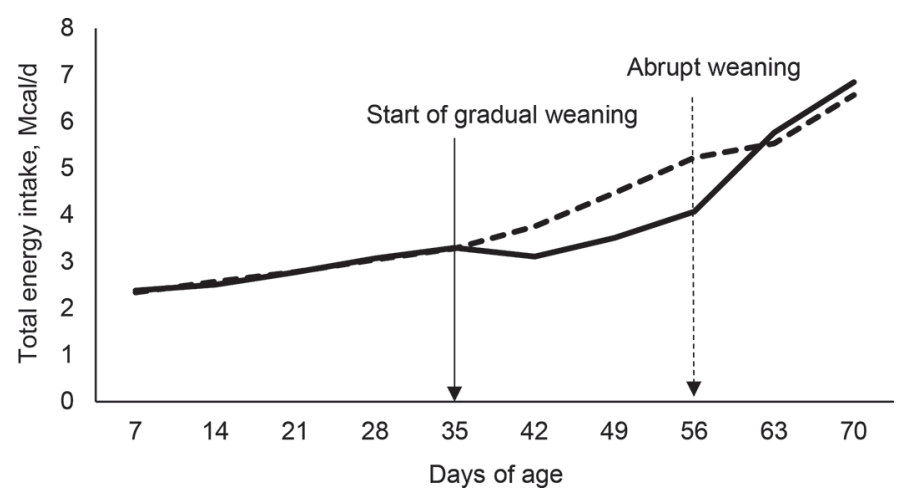

Figure 2. Total energy intake (solid and liquid diet) of calves according to weaning method, abrupt (dashed line) or gradual (solid line).
However, weaning method affected the time spent eating starter $(P=0.002)$, with higher values for gradually weaned calves. Neither nonnutritive oral behavior nor vocalization was affected by the studied factors $(P>$ $0.05)$. However, a day effect was found in the number of vocalizations $(P<0.001)$, with a tendency $(P=0.08)$ for a lower number of vocalizations $2 \mathrm{~d}$ after weaning for gradually weaned calves (Figure 3). Rumination increased with age $(P<0.001)$, but was not affected by weaning method or starter intake level.

\section{DISCUSSION}

The results suggest that the gradual weaning method does not satisfactorily stimulate starter intake in calves with low starter intake at the beginning of the weaning process. This interpretation is in part due to the feeding program of the present study; the supply of 4 $\mathrm{L}$ of milk replacer per day was not a limitation for calf starter intake, as suggested by Gelsinger et al. (2016).

The most important point for calf weaning is the ability to maintain growth and other physiological functions with energy from dry feed. Early in life, this ability is small and increases with accumulated nutrient intake from the starter concentrate, especially with NFC consumption (Quigley et al., 2019). Klopp et al. (2019) have shown that the higher liquid diet intake early in life results in greater feed efficiency, but later on an increase in starter intake is important to maintain feed efficiency through greater fiber digestibility as a result of improved rumen development. Thus, weaning strategies should aim to promote adequate concentrate intake. Gradual weaning was not a useful strategy to increase intake in calves receiving $4 \mathrm{~L} / \mathrm{d}$ of liquid diet that already had low starter intake at $35 \mathrm{~d}$ of age. For these calves, other strategies such as a concentratedependent weaning method, as suggested by Roth et al. (2009), may be more efficient. The calves with low concentrate intake consumed $615.4 \mathrm{~g} / \mathrm{d}$ at weaning, which is lower than what the literature currently recommends for an adequate weaning (Stamey et al., 2012).

Starter intake at young ages may be a multifactorial trait, which includes not only the liquid diet provision, but also characteristics such as personality traits. Neave et al. (2018) found that more exploratory-active calves began consuming starter at an earlier age and showed greater starter DMI during preweaning and postweaning periods and greater overall ADG. The overall health status and disease occurrence also affect starter intake in the preweaning phase. Wenge et al. (2014) reported that a $1 \mathrm{~kg} / \mathrm{d}$ decline in DMI occurred between the day before diarrhea began and the clinical disease resolution. However, the reasons why healthy calves, equally 
Bittar et al.: WEANING METHODS FOR CONVENTIONALLY FED CALVES

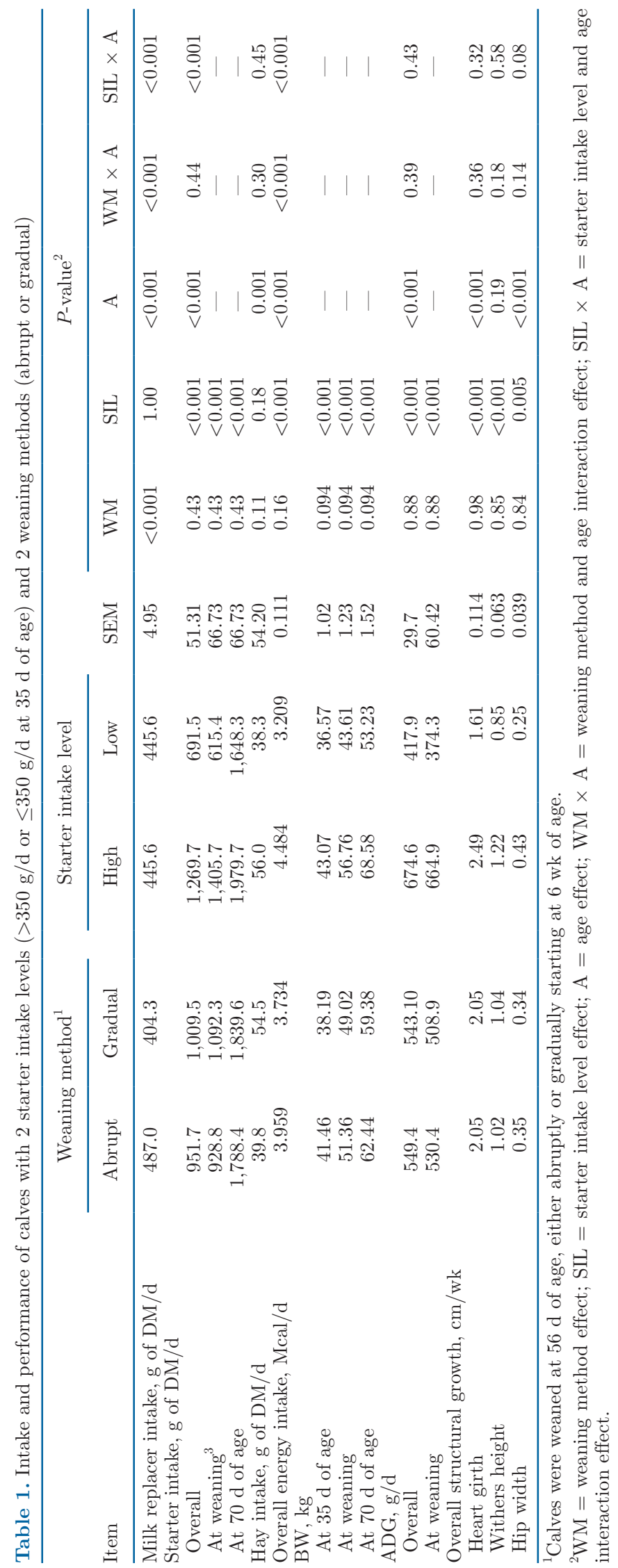

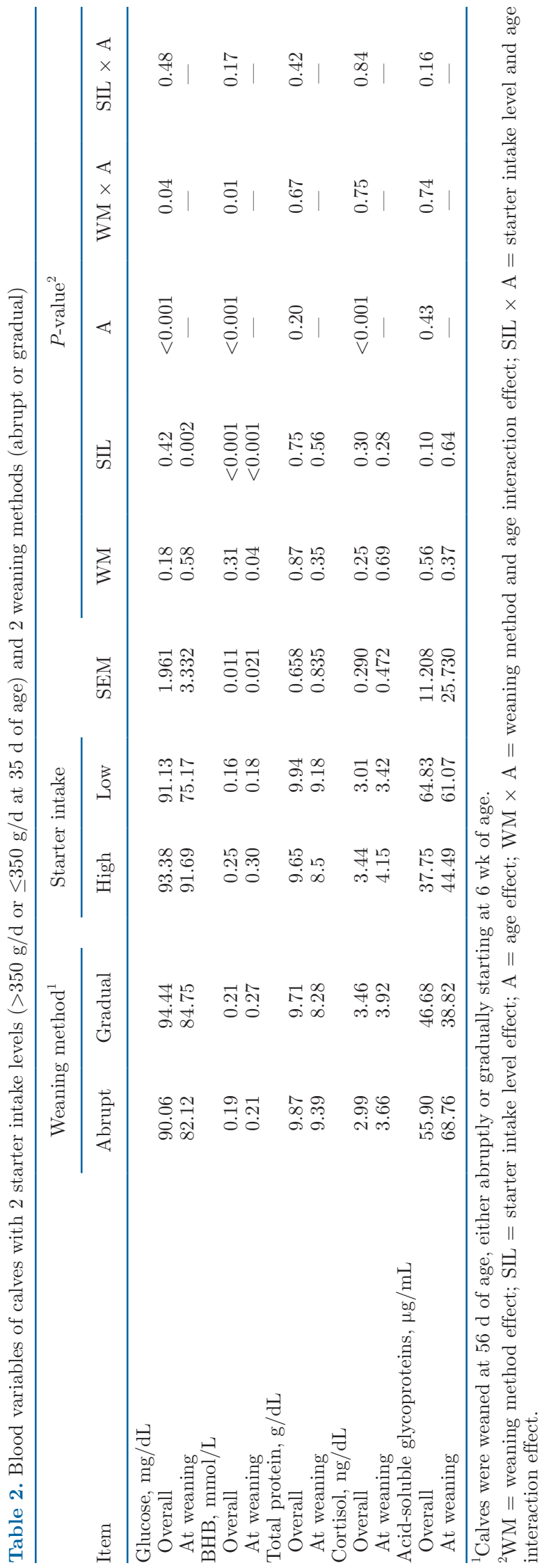




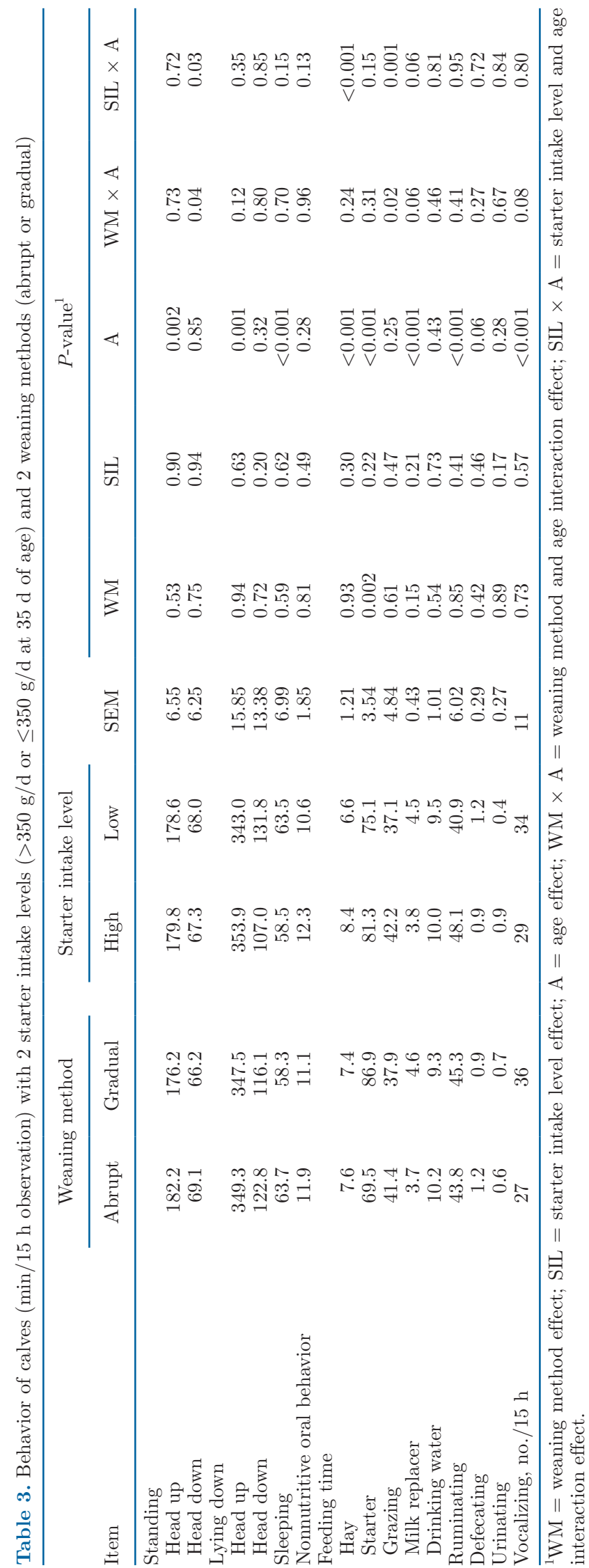

managed, may present marked differences in starter intake should be further studied.

In the present study, calves that had the highest voluntary starter intake at $35 \mathrm{~d}$ of age also presented higher mean BW, weight gain, and structural growth throughout the study period. These results suggest a possible minimum concentrate intake so that the weaning process may begin without jeopardizing performance. Indeed, calves with low starter intake had the lowest performance during the whole period, regardless of the weaning method, showing that gradual weaning was not able to increase the starter intake. Because of the lower milk replacer intake, the reduction in overall energy intake at the beginning of the gradual weaning process may have led to a lack of response in the ADG for this method. Budzynska and Weary (2008) have shown that calves fed $9 \mathrm{~L} / \mathrm{d}$ of liquid diet and consuming $150 \mathrm{~g} / \mathrm{d}$ of starter presented an ADG of $800 \mathrm{~g} / \mathrm{d}$ preweaning, but lost $800 \mathrm{~g} / \mathrm{d}$ during the $3 \mathrm{~d}$ after weaning, even though they increased their concentrate intake. Likewise, de Passillé et al. (2010) observed that the increase in concentrate intake was not enough to compensate for the reduction in energy intake with gradual weaning. The increasing starter intake rate will determine energy intake and therefore the performance of the calves during and after the weaning process. Calves fed lower liquid diet volumes have been assumed to have a faster increase in intake, but the present study showed that this assumption is not always accurate. Consequently, timing to initiate the weaning process should be considered to avoid lower energy intake during the first months of life, regardless of the volume fed.

The reduced performance of calves with low starter intake level, in addition to reinforcing that these animals were not yet physiologically prepared for weaning, may also be related to compromised welfare. Decreased energy intake negatively affects performance but may also increase hunger signs (Veissier et al., 2013). Nevertheless, no weight loss occurred during weaning, even for calves with low starter intake.

Calves with low starter intake had lower plasma concentrations of glucose at the weaning day, probably due to the interruption of milk replacer supply and the fact that they consumed less solid feed. Lower starter intake suggests decreased rumen development, which consequently reduces production of glucose precursors for gluconeogenesis (Gerrits, 2019). When calves have an underdeveloped rumen, the glucose level depends on the liquid diet; therefore, weaning resulted in reduced circulating glucose.

Although other factors may interfere with the plasma concentration of $\mathrm{BHB}$, this metabolite increases with the starter concentrate intake and can be taken as a 
measure of physiological maturation of the ruminal epithelium (Suarez-Mena et al., 2017). As expected, calves with the highest starter intake had the highest concentration of BHB. Gradual weaning did not promote further maturation of the epithelium, as seen by the gradual protocol having no effect on BHB levels.

Acid-soluble glycoproteins may be an indicator that animals are experiencing inflammatory processes due to metabolic disturbances or stress. All calves had values within the normal range (up to $200 \mathrm{mg} / \mathrm{mL}$; Rinaldi et al., 2008); therefore, even abrupt weaning did not cause severe stress. Cortisol concentrations corroborate this interpretation. Even though the cortisol concentration increased slightly on weaning day, the magnitude of this increase does not suggest that animals had physiological stress due to the weaning. Hulbert et al. (2011) reported that comparisons of weaned calves between 24 and $45 \mathrm{~d}$ of age or 45 to $60 \mathrm{~d}$ of age revealed that only younger calves (24 and $45 \mathrm{~d}$ of age) had increased plasma concentrations of cortisol, suggesting that older calves are generally less stressed at weaning. Although glucocorticoid secretion is a classic response to stress-
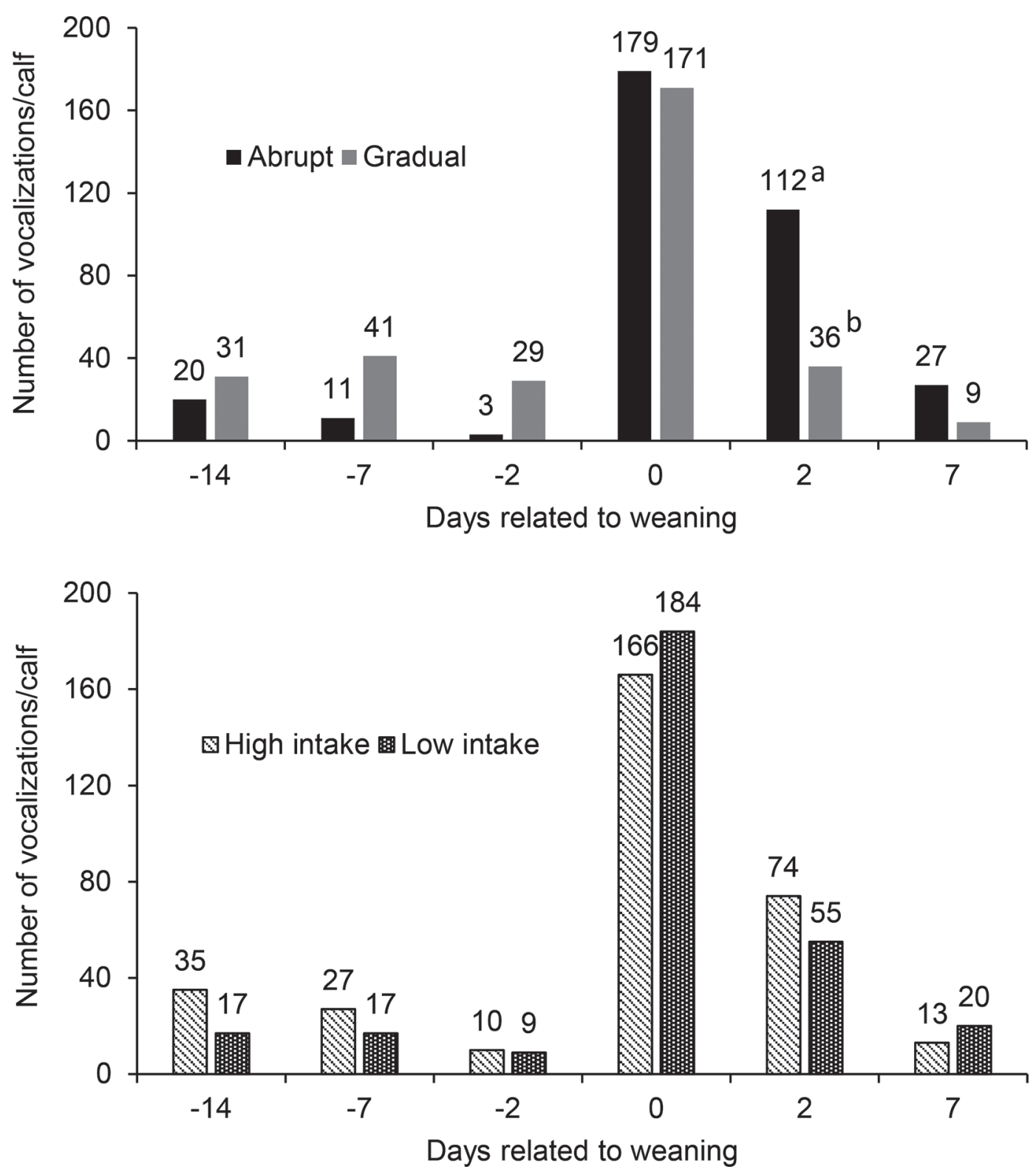

Figure 3. Number of vocalizations of calves according to weaning method (abrupt or gradual) and to level of starter intake ( $>350 \mathrm{~g} / \mathrm{d}$ or $\leq 350 \mathrm{~g} / \mathrm{d}$ at $35 \mathrm{~d}$ of age). Different letters (a, b) indicate significant differences at the $P<0.05$ level. 
ful events, responses to physiological events such as infection are greater than management or a nutritional stimulus such as weaning.

However, other indicators such as vocalization are usually related to weaning stress or frustration. Calves usually vocalize during the feeding period as a response to weaning (Thomas et al., 2001). In the present study, calves vocalized more on the weaning day and during the second day, with vocalizations declining in the following week when the expectation of receiving the liquid diet had decreased, similar to observations reported by Jasper et al. (2008). On the day of weaning, calves vocalized equally, showing that level of starter intake or weaning program did not attenuate immediate stress. However, on the second day after weaning, abruptly weaned calves vocalized more than calves that were gradually weaned, with no differences according to starter intake level.

Activities such as nonnutritive oral behaviors are also considered typical behaviors of calves that are artificially fed. In a study evaluating activities of nonnutritive oral behaviors and vocalization, de Passillé et al. (2010) concluded that these behaviors are mainly due to the low energy intake caused by milk reduction. In the present study, even though gradually weaned calves had lower energy intake, no effects on this behavior were observed. Other factors, such as natural sucking motivation or feeding milk in an open bucket without a teat (as used in this experiment), may lead to the development of nonnutritive oral behaviors (de Passillé et al., 2010), which were not mitigated by the different weaning strategies studied. Although nonnutritional oral behaviors close to weaning are common, we also found no effect of age on this behavior. Miller-Cushon and DeVries (2015) concluded that the reduction of negative behaviors can directly affect the performance and health of dairy calves and that behaviors learned in the first weeks of life are able to influence well-being over long periods of time, reflecting the productive life of the animal.

Although concentrate intake was similar with both weaning methods, gradually weaned calves spent more time eating than the abruptly weaned calves. The time spent eating hay was higher on weaning day when the hay was first fed to the animals, suggesting that neophobia behavior was not a factor. These findings show that gradual weaning can benefit the behavioral aspect, although it does not improve solid feed intake if calves already have low starter intake.

\section{CONCLUSIONS}

For calves fed a restricted volume of milk replacer (4 $\mathrm{L} / \mathrm{d}$ ), the level of starter concentrate intake $3 \mathrm{wk}$ before weaning is more important to performance than the weaning method per se because gradual weaning was not effective in increasing solid feed intake. A minimum concentrate intake should be evaluated prior to a successful gradual weaning process. However, although gradual weaning had no effect on ADG, it reduced vocalization on d 2 postweaning.

\section{ACKNOWLEDGMENTS}

The authors express their appreciation for the financial support provided by the São Paulo Research Foundation (FAPESP, São Paulo, Brazil) as a scholarship (2011/01349-1) and for the financial support for publication (2017/13601-3). The authors have not stated any conflicts of interest.

\section{REFERENCES}

Bach, A., J. Ahedo, and A. Ferrer. 2010. Optimizing weaning strategies of dairy replacement calves. J. Dairy Sci. 93:413-419. https:/ /doi.org/10.3168/jds.2009-2682.

Bradford, M. M. 1976. A rapid and sensitive method for the quantification of microgram quantities of protein utilizing the principle of protein-dye binding. Anal. Biochem. 72:248-254. https://doi.org/ 10.1016/0003-2697(76)90527-3.

Budzynska, M., and D. M. Weary. 2008. Weaning distress in dairy calves: Effects of alternative weaning procedures. Appl. Anim. Behav. Sci. 112:33-39. https://doi.org/10.1016/j.applanim.2007.08 .004 .

De Passillé, A. M., B. Sweeney, and J. Rushen. 2010. Cross-sucking and gradual weaning of dairy calves. Appl. Anim. Behav. Sci. 124:11-15. https://doi.org/10.1016/j.applanim.2010.01.007.

Eckert, E., H. E. Brown, K. E. Leslie, T. J. DeVries, and M. A. Steele. 2015. Weaning age affects growth, feed intake, gastrointestinal development, and behavior in Holstein calves fed an elevated plane of nutrition during the preweaning stage. J. Dairy Sci. 98:6315-6326. https://doi.org/10.3168/jds.2014-9062.

Gelsinger, S. L., A. J. Heinrichs, and C. M. Jones. 2016. A metaanalysis of the effects of preweaned calf nutrition and growth on first-lactation performance. J. Dairy Sci. 99:6206-6214. https:// doi.org/10.3168/jds.2015-10744.

Gerrits, W. J. J. 2019. Symposium review: Macronutrient metabolism in the growing calf. J. Dairy Sci. 102:3684-3691. https://doi.org/ $10.3168 /$ jds.2018-15261.

Greenwood, R. H., J. L. Morrill, and E. C. Titgemeyer. 1997. Using dry feed intake as a percentage of initial body weight as a weaning criterion. J. Dairy Sci. 80:2542-2546. https://doi.org/10.3168/jds .s0022-0302(97)76208-8.

Hill, T. M., H. G. Bateman II, J. D. Quigley III, J. M. Aldrich, R. L. Schlotterbeck, and A. J. Heinrichs. 2013. REVIEW: New information on the protein requirements and diet formulation for dairy calves and heifers since the Dairy NRC 2001. Prof. Anim. Sci. 29:199-207. https://doi.org/10.15232/S1080-7446(15)30225-4.

Hulbert, L. E., C. J. Cobb, J. A. Carroll, and M. A. Ballou. 2011. The effects of early weaning on innate immune responses of Holstein calves. J. Dairy Sci. 94:2545-2556. https://doi.org/10.3168/ jds.2010-3983.

Jasper, J., M. Budzynska, and D. M. Weary. 2008. Weaning distress in dairy calves: Acute behavioural responses by limit-fed calves. Appl. Anim. Behav. Sci. 110:136-143. https://doi.org/10.1016/j .applanim.2007.03.017.

Kertz, A. F., L. R. Prewitt, and J. P. Everett Jr.. 1979. An early weaning calf program: Summarization and review. J. Dairy Sci. 
62:1835-1843. https://doi.org/10.3168/jds.S0022-0302(79)83508 $-0$.

Klopp, R. N., F. X. Suarez-Mena, T. S. Dennis, T. M. Hill, R. L. Schlotterbeck, and G. J. Lascano. 2019. Effects of feeding different amounts of milk replacer on growth performance and nutrient digestibility in Holstein calves to 2 months of age using different weaning strategies. J. Dairy Sci. 102:11040-11050. https://doi .org/10.3168/jds.2019-17153.

Larson, L. L., F. G. Owen, J. L. Albright, R. D. Appleman, R. C. Lamb, and L. D. Muller. 1977. Guidelines toward more uniformity in measuring and reporting calf experimental data. J. Dairy Sci. 60:989-991. https://doi.org/10.3168/jds.S0022-0302(77)83975-1.

Lomborg, S. R., L. R. Nielsen, P. M. H. Heegaard, and S. Jacobsen. 2008. Acute phase proteins in cattle after exposure to complex stress. Vet. Res. Commun. 32:575-582. https://doi.org/10.1007/ s11259-008-9057-7.

Miller-Cushon, E. K., and T. J. DeVries. 2011. Technical note: Validation of methodology for characterization of feeding behavior in dairy calves. J. Dairy Sci. 94:6103-6110. https://doi.org/10.3168/ jds.2011-4589.

Miller-Cushon, E. K., and T. J. DeVries. 2015. Invited review: Development and expression of dairy calf feeding behavior. Can. J. Anim. Sci. 95:341-350. https://doi.org/10.4141/cjas-2014-163.

Nakajima, K. T., Y. Kodaira, H. Ichioka, S. Nilla, H. Nagakawa, S. Yamamoto, H. Chikakiyo, and H. Ohtani. 1982. A new method for serum mucoprotein (acid soluble glycoproteins) assay using Coomassie brilliant blue G-250. Japan. J. Clin. Chem. 11:214-221. https://doi.org/10.14921/jscc1971b.11.3_214. [In Japanese]

Neave, H. W., J. H. C. Costa, D. M. Weary, and M. A. G. von Keyserlingk. 2018. Personality is associated with feeding behavior and performance in dairy calves. J. Dairy Sci. 101:7437-7449. https:// doi.org/10.3168/jds.2017-14248.

Quigley, J. D., III. 1996. Feeding prior to weaning. Pages 245-255 in Proceedings of Calves, Heifers and Dairy Profitability National Conference, Harrisburg, PA. Northeast Regional Agricultural Engineering (NRAES) Service, Cooperative Extension, Ithaca, NY.

Quigley, J. D., W. Hu, J. R. Knapp, T. S. Dennis, F. X. Suarez-Mena, and T. M. Hill. 2019. Estimates of calf starter energy affected by consumption of nutrients. 1. Evaluation of models to predict changing digestion on energy content in calf starters. J. Dairy Sci. 102:2232-2241. https://doi.org/10.3168/jds.2018-15353.

Rinaldi, M., F. Ceciliani, C. Lecchi, P. Moroni, and D. D. Bannerman. 2008. Differential effects of $\alpha 1$-acid glycoprotein on bovine neutrophil respiratory burst activity and IL-8 production. Vet. Immunol. Immunopathol. 126:199-210. https://doi.org/10.1016/j .vetimm.2008.07.001.

Roth, B. A., N. M. Keil, L. Gygax, and E. Hillmann. 2009. Influence of weaning method on health status and rumen development in dairy calves. J. Dairy Sci. 92:645-656. https://doi.org/10.3168/ jds.2008-1153.

Santos, G., and C. M. M. Bittar. 2015. A survey of dairy calf management practices in some producing regions in Brazil. Rev. Bras. Zootec. 44:361-370. https://doi.org/10.1590/S1806 $-92902015001000004$.

Stamey, J. A., N. A. Janovick, A. F. Kertz, and J. K. Drackley. 2012. Influence of starter protein content on growth of dairy calves in an enhanced early nutrition program. J. Dairy Sci. 95:3327-3336. https://doi.org/10.3168/jds.2011-5107.

Steele, M. A., J. H. Doelman, L. N. Leal, F. Soberon, M. Carson, and J. A. Metcalf. 2017. Abrupt weaning reduces postweaning growth and is associated with alterations in gastrointestinal markers of development in dairy calves fed an elevated plane of nutrition during the preweaning period. J. Dairy Sci. 100:5390-5399. https:// doi.org/10.3168/jds.2016-12310.

Suarez-Mena, F. X., W. Hu, T. S. Dennis, T. M. Hill, and R. L. Schlotterbeck. 2017. $\beta$-Hydroxybutyrate (BHB) and glucose concentrations in the blood of dairy calves as influenced by age, vaccination stress, weaning, and starter intake including evaluation of BHB and glucose markers of starter intake. J. Dairy Sci. 100:2614-2624. https://doi.org/10.3168/jds.2016-12181.

Sweeney, B. C., J. Rushen, D. M. Weary, and A. M. De Passilé. 2010. Duration of weaning, starter intake and weight gain of dairy calves fed large amounts of milk. J. Dairy Sci. 93:148-152. https://doi .org/10.3168/jds.2009-2427.

Thomas, T. J., D. M. Weary, and M. C. Appleby. 2001. Newborn and 5 -week-old calves vocalize in response to milk deprivation. Appl. Anim. Behav. Sci. 74:165-173. https://doi.org/10.1016/S0168 -1591(01)00164-2.

USDA-APHIS. 2014. Dairy Cattle Management Practices in the United States, 2014. National Animal Health Monitoring System. https://www.aphis.usda.gov/animal_health/nahms/dairy/ downloads/dairy14/Dairy14_dr_PartI_1.pdf.

Vasseur, E., J. Rushen, A. M. de Passillé, D. Lefebvre, and D. Pellerin. 2010. An advisory tool to improve management practices affecting calf and heifer welfare on dairy farms. J. Dairy Sci. 93:4414-4426. https://doi.org/10.3168/jds.2009-2586.

Veissier, I., S. Caré, and D. Pomiès. 2013. Suckling, weaning, and the development of oral behaviours in dairy calves. Appl. Anim. Behav. Sci. 147:11-18. https://doi.org/10.1016/j.applanim.2013.05 .002 .

Wenge, J. I., C. Steinhöfel, M. Heinrich, L. Coenen, and L. Bachmann. 2014. Water and concentrate intake, weight gain and duration of diarrhea in young suckling calves on different diets. Livest. Sci. 159:133-140. https://doi.org/10.1016/j.livsci.2013.11.004. 